\title{
Investigation on Microsegregation of IN718 Alloy During Additive Manufacturing via Integrated Phase-Field and Finite-Element Modeling
}

\author{
X. Wang, P.W. Liu, Y. Ji, Y. Liu, M.H. Horstemeyer, and L. Chen
}

(Submitted April 2, 2018; in revised form July 20, 2018; published online August 29, 2018)

\begin{abstract}
In this work, we apply a multi-scale model combining finite-element method (FEM) and phase-field model (PFM) to simulate the evolution of solidification microstructures at different locations within a molten pool of an additively manufactured IN718 alloy. Specifically, the FEM is used to calculate the shape of molten pool and the relative thermal gradient $G$ at the macroscale. Then, the calculated thermal information is input into PFM for microstructure simulation. Finally, the morphology of solidification structures and formation of Laves phase at different sites are studied and compared. We found that the solidification site with a large angle between the temperature gradient and the preferred crystalline orientation could build up a high niobium $(\mathrm{Nb})$ concentration in the liquid during solidification but has less possibility of forming continuous long chain morphology of Laves phase particles. This finding provides an understanding of the microstructure evolution inside the molten pool of IN718 alloy during solidification. Further, the finding indicates that the site with a large misorientation angle will have a good hot cracking resistance after solidification.
\end{abstract}

Keywords Laves phase, micro-segregation, phase-field simulation, solidification microstructure

\section{Introduction}

Due to high efficiency and low cost, the laser additive manufacturing (AM) (specially, laser powder bed fusion additive manufacturing) has been particularly of interest in the rapid component manufacturing and parts repairing. AM of nickel-based superalloys (Ref 1-4) attracts extensive research interests. As a precipitation-strengthened Nb-bearing superalloy, IN718 shows excellent mechanical properties (Ref 5,6). These mechanical properties are related to the formation of microstructures, e.g., cell/dendrite spacing and micro-segregation, during solidification. Several experimental and numerical studies were focused on the microstructure features of $\mathrm{Ni}-\mathrm{Nb}$ alloy during AM (Ref 7-9). Specifically (Ref 10), solidification conditions including temperature gradient $G$, pulling speed $V_{\mathrm{p}}$

This article is an invited paper selected from presentations at the symposium "Modeling and Simulation in Additive Manufacturing: Materials Design, Property Prediction, and Process Control," held during MS\&T'17, October 8-12, 2017, in Pittsburgh, PA, and has been expanded from the original presentation.

X. Wang, Y. Liu, M. H. Horstemeyer, and L. Chen, Department of Mechanical Engineering, Mississippi State University, Mississippi State, MS 39762, USA; P. W. Liu, Department of Mechanical Engineering, Mississippi State University, Mississippi State, MS 39762, USA; and State Key Laboratory of Advanced Design and Manufacturing for Vehicle Body, Hunan University, Changsha 410082 , People's Republic of China; and and Y. Ji, Department of Materials Science and Engineering, The Pennsylvania State University, University Park, PA 16802, USA. Contact e-mail: chen@me.msstate.edu. and cooling rate $\partial T / \partial t$ are critical to the evolution of solidification structures. Changing those conditions can easily alter the solidification morphologies from tilted dendrites to seaweed-like structures (Ref 11, 12). In addition, during AM of IN718, Nb is segregated into the liquid that controls the formation of the Laves phases (Ref 13), which can dramatically reduce the performance of IN718 (Ref 14). Although Fe and Ti may also contribute to the formation of Laves phase, the role of $\mathrm{Nb}$ segregation is more critical (Ref 13, 15-17). Hence, understanding the formation of Laves phase becomes a challenge to effectively improve the ultimate tensile strength, fracture toughness, hot crack resistance and fatigue life, of IN718 superalloy.

Since the direct observation of microstructure evolution by experimental technology is very difficult due to the rapid solidification during manufacturing process, numerical simulation becomes a necessary alternative method, i.e., phase-field method (PFM) [applied to a vast range of materials phenomena including solidification and solid-state phase transformation (Ref 18-22)] and cellular automaton (CA). Nie et al. (Ref 23) combined finite-element method (FEM) and CA to study the influence of solidification conditions (i.e., the cooling rate and the temperature gradient) on the formation of Laves phase particles during AM. Ghosh et al. (Ref 24) investigated the primary spacing and micro-segregation in laser deposited Ni$\mathrm{Nb}$ alloys by combing FEM and PFM. However, in these simulations, zero misorientation between the preferred crystalline orientation and the temperature gradient direction is assumed in the simulation domain. In realistic laser AM process, the solidification conditions are not always homogenous along the solid-liquid interface in the molten alloy. Moreover, the evolution of solidification microstructure can be impacted by the location of domain in the molten pool, i.e., the pulling speed $V_{\mathrm{p}}$ varies depending on the position of solidification sites (as well as temperature gradient $G$ ) (Ref 25). Yu et al. (Ref 26) investigated the evolution of solidification 
microstructure by considering different misorientation angles in a gas tungsten arc welding molten pool of an $\mathrm{Al}-4 \mathrm{wt} \% \mathrm{Cu}$ alloy. They found that the solidification microstructure varies from tilted dendrites to degenerated seaweeds as the misorientation angle increases. Therefore, it is necessary to investigate the morphology and distribution of the Laves phase particles under the influence of solidification site (i.e., the misorientation angles).

The goal of this work is to investigate the influence of solidification site on the solidification structures and formation of Laves phase of IN718 alloy during laser AM. A multi-scale model combining FEM and PFM is applied. Specifically, we employ FEM to obtain the geometry of molten pool and $G$ at the macroscale, and then input them to PFM for simulation of dendrite growth at the microscale. Finally, the morphology of solidification structures and formation of Laves phase at different sites (different misorientation angles) are compared.

\section{Methodology}

\subsection{Finite-Element-Based Thermal Model}

To obtain the molten pool geometry, relative temperature field and thermal gradient during laser AM of IN718, an FEM-based heat transfer simulation is conducted based on ABAQUS ${ }^{\mathrm{TM}}$ platform, which is governed by the heat conduction equation

Table 1 Physical properties of IN718 superalloy and related parameters (Ref 23, 24)

\begin{tabular}{lll}
\hline Symbol & \multicolumn{1}{c}{ Value } & Unit \\
\hline Liquidus temperature, $T_{\mathrm{L}}$ & 1678 & $\mathrm{~K}$ \\
Solidus temperature, $T_{\mathrm{s}}$ & 1643 & $\mathrm{~K}$ \\
Initial solute solution, $c_{\infty}$ & 5.0 & $\mathrm{wt} \%$ \\
Liquid diffusion coefficient, $D$ & $3.0 \times 10^{-9}$ & $\mathrm{~m}^{2} \mathrm{~s}^{-1}$ \\
Liquidus slope, $m$ & -10.5 & $\mathrm{~K} / \mathrm{wt} \%$ \\
Anisotropy of surface energy, $\varepsilon_{0}$ & 0.03 & $\ldots$ \\
Equilibrium partition coefficient, $k_{\mathrm{e}}$ & 0.48 & $\ldots$ \\
Gibbs-Thomson coefficient, $\Gamma$ & $3.65 \times 10^{-7}$ & $\mathrm{~K} \mathrm{~m}$ \\
Capillary length, $d_{0}$ & $8.0 \times 10^{-9}$ & $\mathrm{~m}$
\end{tabular}

The solute concentration is normalized and represented by weight percentage, as "wt.\%". $\nabla \cdot(\kappa \nabla T)+q_{\text {laser }}=\frac{\partial(\rho H(T))}{\partial t}$

where $T$ is the temperature, $\kappa$ is the thermal conductivity, $\rho$ represents the density, $t$ is the time and $H(T)$ is the enthalpy per unit mass, which incorporates the latent heat of phase change (Ref 27). $q_{\text {laser }}$ is the laser energy simulated using a Gaussian heat source (Ref 24).

Consider the high difference of temperature between the printed component and ambient, the convection and radiation boundary conditions are imposed on the surface

$\kappa \nabla \cdot T=h_{\mathrm{cc}}\left(T_{\mathrm{a}}-T\right)+\varepsilon_{R} k_{\mathrm{SB}}\left(T_{\mathrm{a}}^{4}-T^{4}\right)$

where $T_{\mathrm{a}}$ is ambient temperature, $h_{\mathrm{cc}}$ is the heat convection coefficient, $\varepsilon_{R}, k_{\mathrm{SB}}$ are the thermal radiation coefficient and Stefan-Boltzmann constant, respectively.

\subsection{Phase Field Modeling}

The microstructural pattern formation during AM of IN718 is predicted by the quantitative PFM developed by Echebarria et al. (Ref 28). The "frozen temperature approximation" is adopted in which an imposed temperature gradient $G$ is translated along the $z$ axis following $T=T_{0}+G\left(z-V_{\mathrm{p}} t\right)$, where $T_{0}(z=0, t=0)$ is a reference temperature. In the PFM, a scalar variable $\phi$ is introduced to distinguish the type of phases at a fixed point and time. The field $\phi$ takes on the value $\phi=-1$ in the liquid phase and $\phi=1$ in the solid phase and varies smoothly across the diffuse interface. The solute concentration $c$ is characterized by a generalized supersaturation field $U$ :

$U=\frac{1}{1-k_{\mathrm{e}}}\left(\frac{2 k_{\mathrm{e}} c / c_{\infty}}{1+k_{\mathrm{e}}-\left(1-k_{\mathrm{e}}\right) \phi}-1\right)$

where $k_{\mathrm{e}}$ is the partition coefficient, $c_{\infty}$ is the average solute concentration in the far-away field. For cubic crystals such as IN718, the fourfold surface energy anisotropy function in 2-D system is approximated as

$a(\hat{n}) \equiv a(\theta)=1+\varepsilon_{0} \cos 4 \theta$

where $\varepsilon_{0}$ is the anisotropy strength, $\theta$ is the angle between the interface normal and the axis $z$ with $\theta=\arctan \left(\partial_{z} \phi / \partial_{x} \phi\right)$. Equation 4 can be further modified as

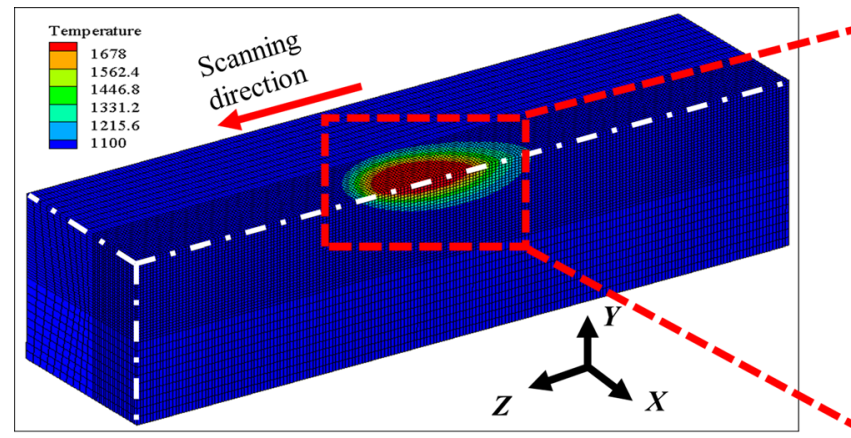

(a)

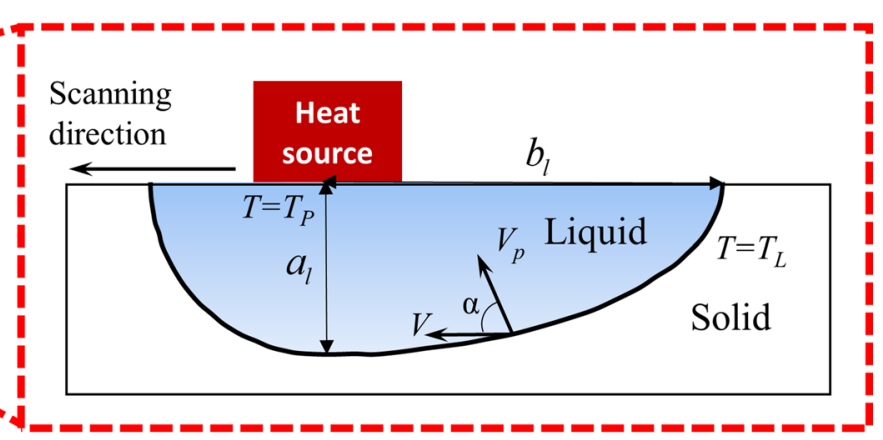

(b)

Fig. 1 (a) A representative temperature contour at the macroscale, of which unit is in Kevin (K); (b) schematic of the molten pool. The realtime information, including shape of the molten pool, temperature field and thermal gradient, can be extracted from the thermal model 

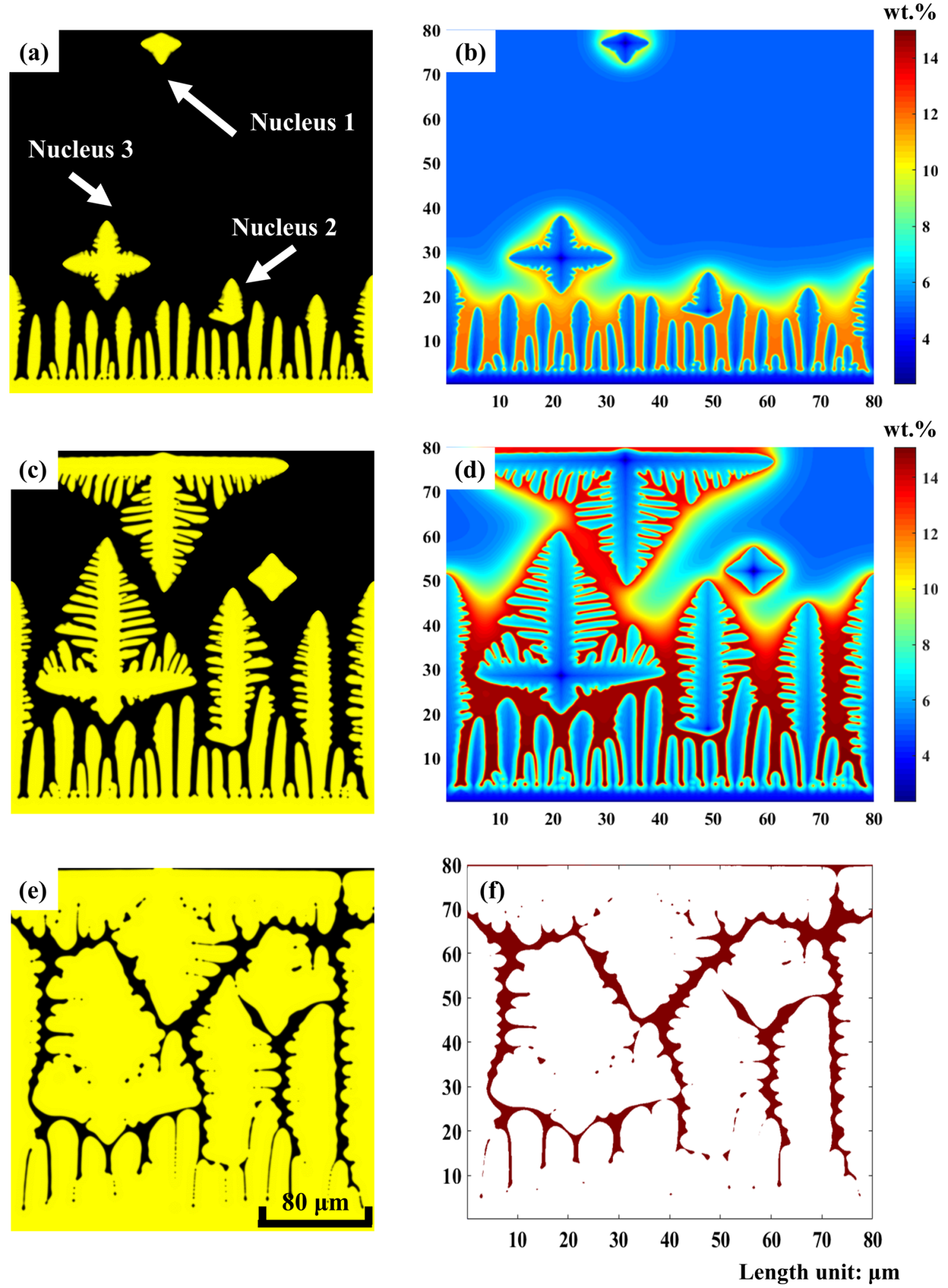

Fig. 2 Simulated evolution of microstructure during solidification (misorientation angle $\theta_{0}=0^{\circ}$ ). Nucleation and growth of dendrites at $t=10,000 \Delta t\left(1.61 \times 10^{-3} \mathrm{~s}\right)$ with (a) the phase contour and (b) the solute concentration of $\mathrm{Nb}$, at $t=17,000 \Delta t\left(2.74 \times 10^{-3} \mathrm{~s}\right)(\mathrm{c})$ the phase contour and (d) the solute concentration of $\mathrm{Nb}$, and at $t=50,000 \Delta t\left(8.05 \times 10^{-3} \mathrm{~s}\right)$ with (e) the phase contour and (f) the distribution of Laves phase particles. The domain size is $80 \mu \mathrm{m} \times 80 \mu \mathrm{m}$ 
wt. $\%$
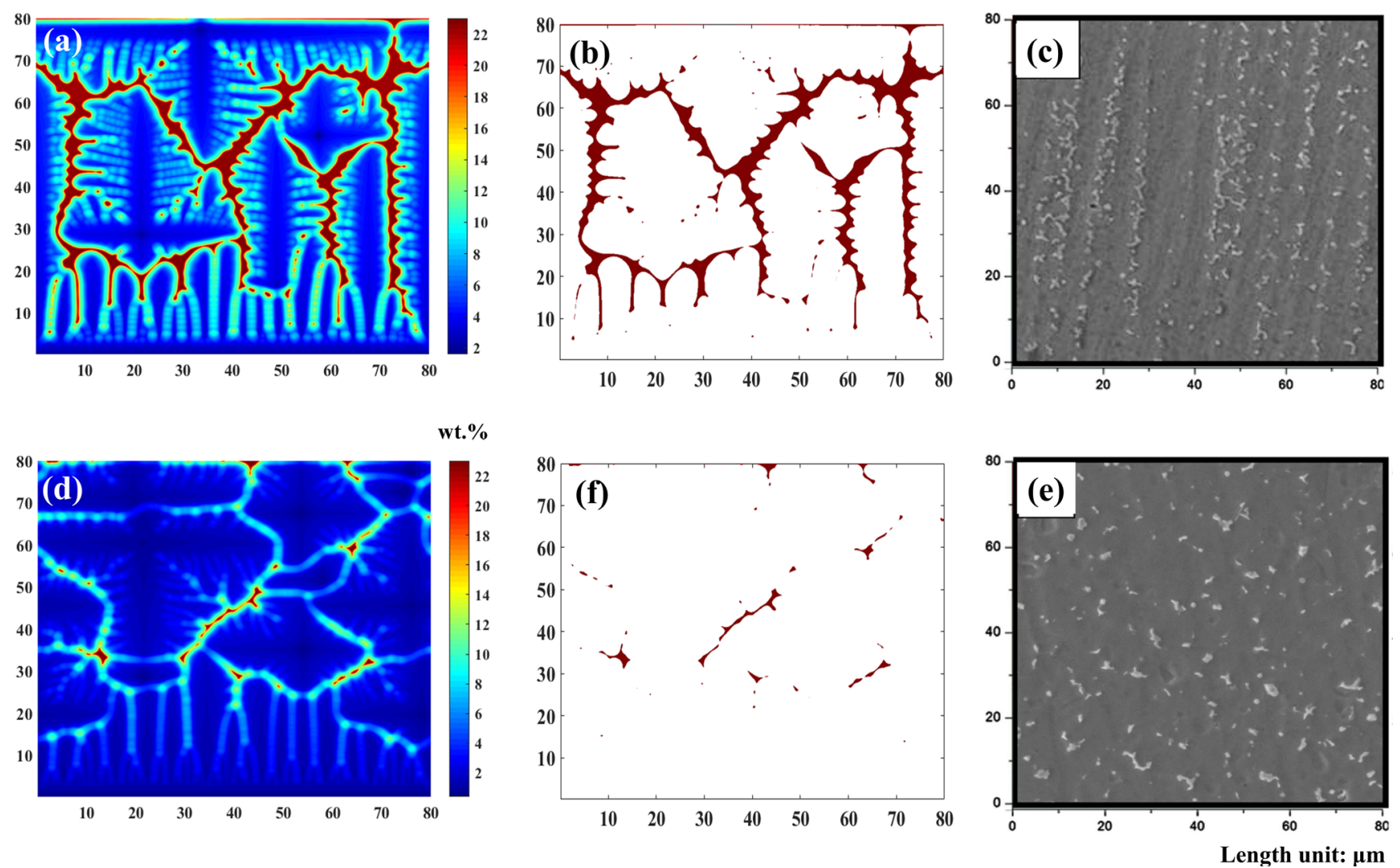

Fig. 3 Morphology of Laves phases particles during solidification with the misorientation angle $\theta_{0}=0^{\circ}$ at a low cooling rate: $1000 \mathrm{~K} \mathrm{~s}^{-1}$ (a) the solute concentration of $\mathrm{Nb}$, (b) the distribution of Laves phase particles and (c) observation (Ref 23); and at a high cooling rate: $4000 \mathrm{~K} \mathrm{~s}{ }^{-1}$ (d) the solute concentration of $\mathrm{Nb}$, (e) the distribution of Laves phase particles and (e) observation (Ref 23)

$a(\widehat{n}) \equiv a\left(\theta+\theta_{0}\right)=1+\varepsilon_{0} \cos 4\left(\theta+\theta_{0}\right)$, in which $\theta_{0}$ means the misorientation angle between the preferred crystalline orientation and the temperature gradient direction.

The governing equations of $\phi$ and $U$ are expressed as follows (Ref 28)

$$
\begin{aligned}
\tau_{0} a & (\hat{n})\left[1-\left(1-k_{\mathrm{e}}\right) \frac{z-V_{\mathrm{p}} t}{l_{\mathrm{T}}}\right] \frac{\partial \phi}{\partial t} \\
& =\vec{\nabla} \cdot\left[W(\hat{n})^{2} \vec{\nabla} \phi\right]+\phi-\phi^{3}-\lambda g(\phi)\left[U+\frac{z-V_{\mathrm{p}} t}{l_{\mathrm{T}}}\right]
\end{aligned}
$$

$$
\begin{aligned}
& \left(\frac{1+k_{\mathrm{e}}}{2}-\frac{1-k_{\mathrm{e}}}{2} \phi\right) \frac{\partial U}{\partial t} \\
& =\vec{\nabla} \cdot\left(D q(\phi) \vec{\nabla} U+a(\hat{n}) W\left[1+\left(1-k_{\mathrm{e}}\right) U\right] \frac{\partial \phi}{\partial t} \frac{\vec{\nabla} \phi}{|\vec{\nabla} \phi|}\right) \\
& \quad+\frac{1}{2}\left[1+\left(1-k_{\mathrm{e}}\right) U\right] \frac{\partial \phi}{\partial t}
\end{aligned}
$$

where $g(\phi)=\left(1-\phi^{2}\right)^{2}$ is the double-well function which ensures $g(-1)=g(1)=0$, the function $q(\phi)=(1-\phi) / 2$ dictates zero solute diffusivity in the solid phase. $D$ is the solute diffusivity in the liquid, $l_{\mathrm{T}}=|m| c_{\infty}\left(1-k_{\mathrm{e}}\right) / k_{\mathrm{e}} / G$ is the thermal length as a function of thermal gradient $G, m$ is the liquidus slope. $W$ and $\tau_{0}$ are length and time scales representing interface width and relaxation time, respectively. Neglecting the kinetic effect, physical quantities $W=d_{0} \lambda / a_{1}$ and $\tau_{0}=a_{2} \lambda W^{2} / D$ are used to linked these parameters, respectively, where $a_{1}=0.8839$ and $a_{2}=0.6267$ are numerical constants, $\lambda$ is the coupling constant, $d_{0}=\Gamma /|m|\left(1-k_{\mathrm{e}}\right) c_{1}^{0}$ is the capillary length, $\Gamma$ is the Gibbs-Thomson coefficient, and $c_{1}^{0}=c_{\infty} / k_{\mathrm{e}}$ is the concentration on the liquid side of the interface. The temperature $T$ is connected with $U$ and $\phi$ through the term $\left(z-V_{\mathrm{p}} t\right) / l_{\mathrm{T}}$, of which $V_{\mathrm{p}}$ is extracted from the melt pool solid-liquid boundary given by the FEA simulations.

\subsection{Simulation Details}

Since we only focus on selected small regions in the molten pool, the AM process can be treated as directional solidification. Using a finite volume method and an explicit time March scheme, Eq 5 and 6 are solved on a uniform mesh with a fixed grid size of $\Delta x / W_{0}=0.8$. The size of the simulation domain is $80 \mu \mathrm{m} \times 80 \mu \mathrm{m}$ with zero-flux boundary conditions for both $\phi$ and $U$. The value of $W_{0}$ is taken as 10 times smaller than the dendrite tip radius (Ref 24), so we use $0.27 \mu \mathrm{m}$ as the maximum interface width, which leads to a coupling constant $\lambda$ of 30. To ensure numerical stability, the maximum time step is taken according to $\Delta t<\Delta x^{2} /(4 D)$. As shown in Table 1 , the thermophysical parameters of IN718 superalloy are referred to Ref 18. 


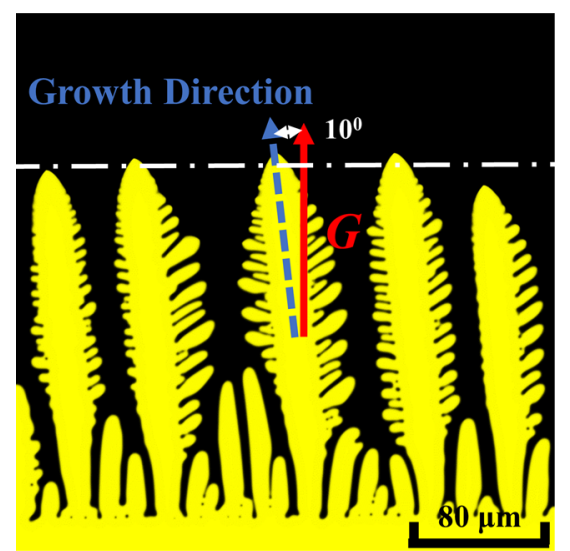

(a)

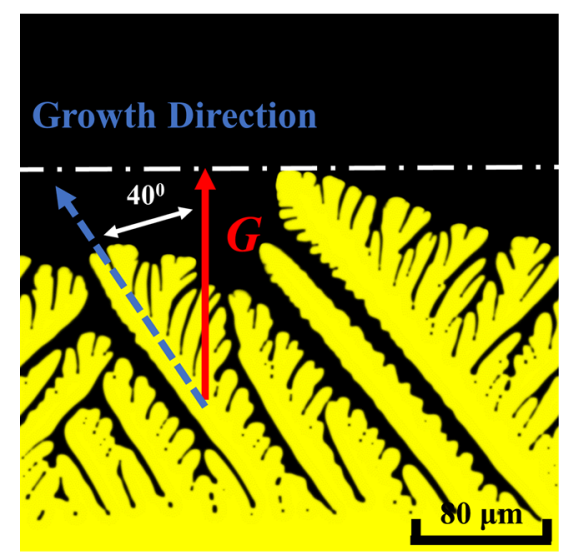

(c)

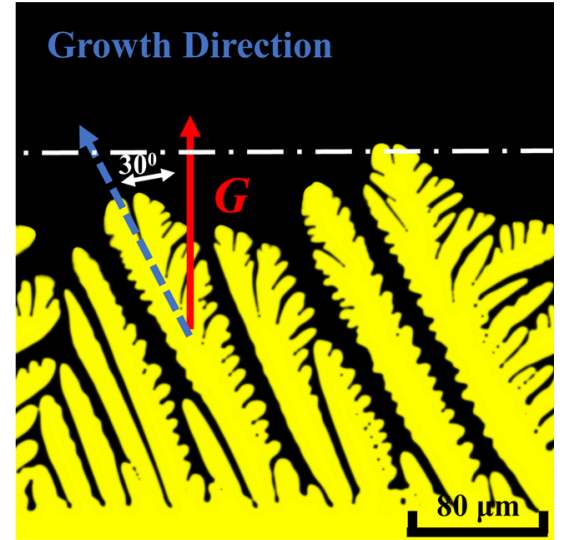

(b)

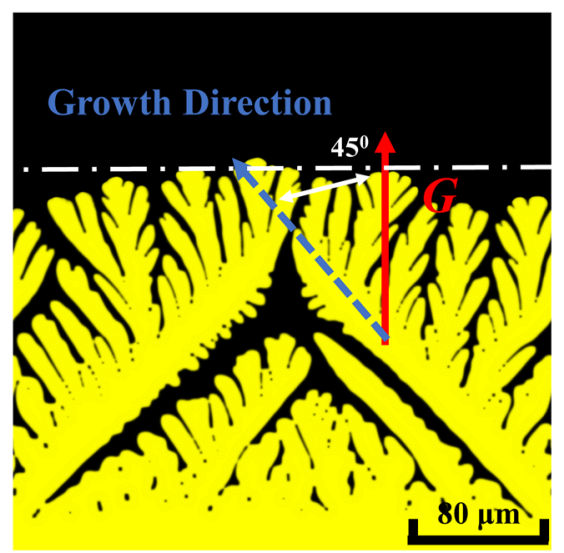

(d)

Fig. 4 Dendrite growth during solidification with different misorientation angles: (a) $\theta_{0}=10^{\circ}$; (b) $\theta_{0}=30^{\circ}$; (c) $\theta_{0}=40^{\circ}$; (d) $\theta_{0}=45^{\circ}$

\section{Results and Discussion}

\subsection{FEM Simulation and Estimates of $G$ and $V_{p}$}

Figure 1(a) displays a representative temperature contour calculated using FEM, and Fig. 1(b) shows the schematic of a 2D molten pool: the blue region reflects the shape of the molten pool, where $a_{1}$ and $b_{1}$ are the depth and rear length. $V$ represents the scanning speed, and the parameter $\alpha$ is the angle between the directions of $V$ and $V_{\mathrm{p}}$ (as the scanning direction and the dendrite growth direction). $T_{\mathrm{P}}$ and $T_{\mathrm{L}}$ are the temperatures of the molten pool center and liquidus line, respectively. The value of $V_{\mathrm{p}}$ follows $V_{\mathrm{p}}=\cos (\alpha) V(\operatorname{Ref} 29)$. Besides, the values $a_{\mathrm{l}}, b_{\mathrm{l}}$, $T_{\mathrm{P}}$ and $T_{\mathrm{L}}$ are obtained from $\mathrm{FEM}\left(a_{1} \approx 0.5 \mathrm{~mm}\right.$ and $b_{1} \approx 1.6$ $\mathrm{mm})$.

The inputs of FEM calculation are: $V=10 \mathrm{~mm} \mathrm{~s}^{-1}$ and with the laser power of $1 \mathrm{~kW}$. From the FEM simulation, we note that $G$ varies between $3.0 \times 10^{6} \mathrm{~K} \mathrm{~m}^{-1}$ at the bottom to $0.5 \times 10^{5} \mathrm{~K} \mathrm{~m}^{-1}$ at the solid-liquid interface along the molten pool boundary. However, compared to the variation of $V_{\mathrm{p}}$ from $0.175 \mathrm{~mm} \mathrm{~s}^{-1}\left(\alpha=89^{\circ}\right)$ to $9.5 \mathrm{~mm} \mathrm{~s}^{-1}\left(\alpha=10^{\circ}\right)$ which is in the range of rapid solidification processing, $G$ plays a minor role in the microstructure selection process (Ref 30, 31). Therefore, we adopt the fixed values of $G\left(10^{5} \mathrm{~K} \mathrm{~m}^{-1}\right)$ and $\alpha=10^{\circ}$ in the following phase field simulation.

\subsection{Model Calibration}

Here, we calibrate the simulation results (including nucleation probability, see "Appendix" for details) with the results from Ref 18. The simulation parameters are referred to Ref 18 under a fixed cooling rate $\left(10^{3} \mathrm{~K} \mathrm{~s}^{-1}\right)$ and temperature gradient $\left(10^{5} \mathrm{~K} \mathrm{~m}^{-1}\right)$; Fig. 2 shows the nucleation and dendrite growth during solidification of IN718. Similar to Ref 18 , the nuclei (i.e., nucleus 1, 2 and 3) appear in the liquid phase during the early stage of solidification and grow into columnar and equiaxed dendrites, respectively, as shown in Fig. 2(a). The nucleation site far away from the solid phase leads to the equiaxed dendrite growth (see Nucleus 1). The nuclei which forms near the solid phase (See Nucleus 2) shows typical columnar morphology. Although a nucleus could formed in the equiaxed mode at the beginning, it essentially grows in columnar mode, due to limit spacing with the adjacent columnar dendrites (see Nucleus 3 in Fig. 2a and c). Figure 2(b) and (d) displays the corresponding solute distribution of $\mathrm{Nb}$, where the growing solute concentration indicates more $\mathrm{Nb}$ being rejected into the liquid as the solidification proceeds. Further, the liquid of the IN718 alloy with a low concentration of $\mathrm{Nb}$ transforms into the austenite phase $(\gamma)$ and liquid with a high concentration of $\mathrm{Nb}$ transforms into the eutectic phase $(\gamma+$ Laves phase) (Ref 23). It shows that eutectic transformation takes place when the concentration of $\mathrm{Nb}$ in the liquid is 


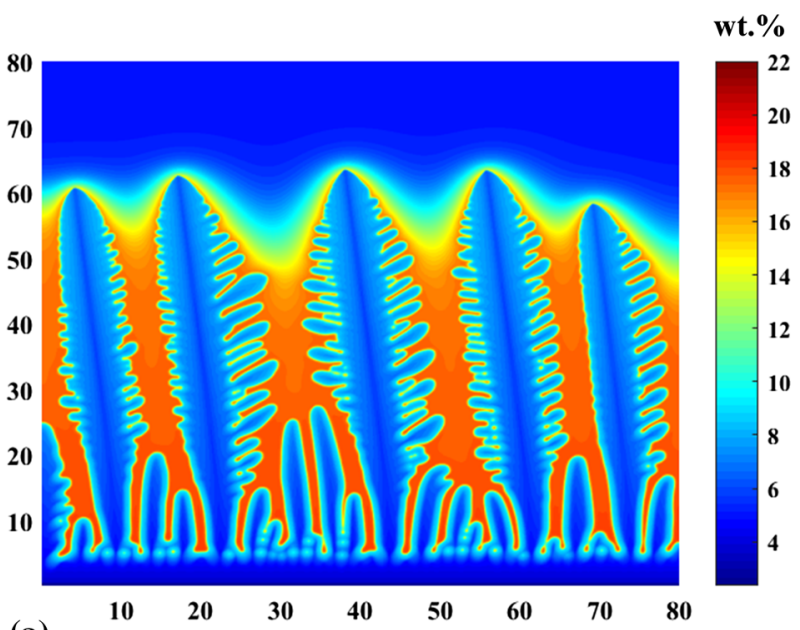

(a)
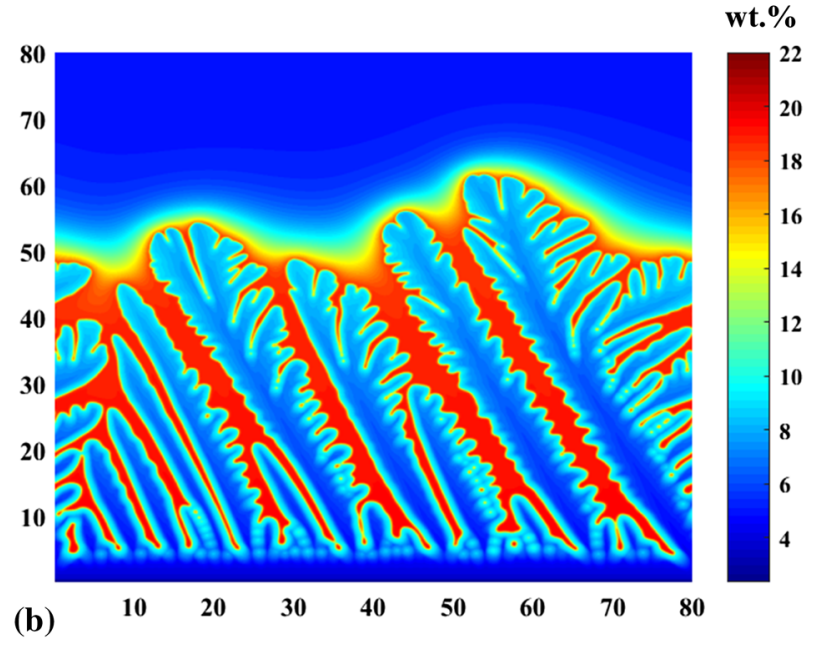

wt.\%
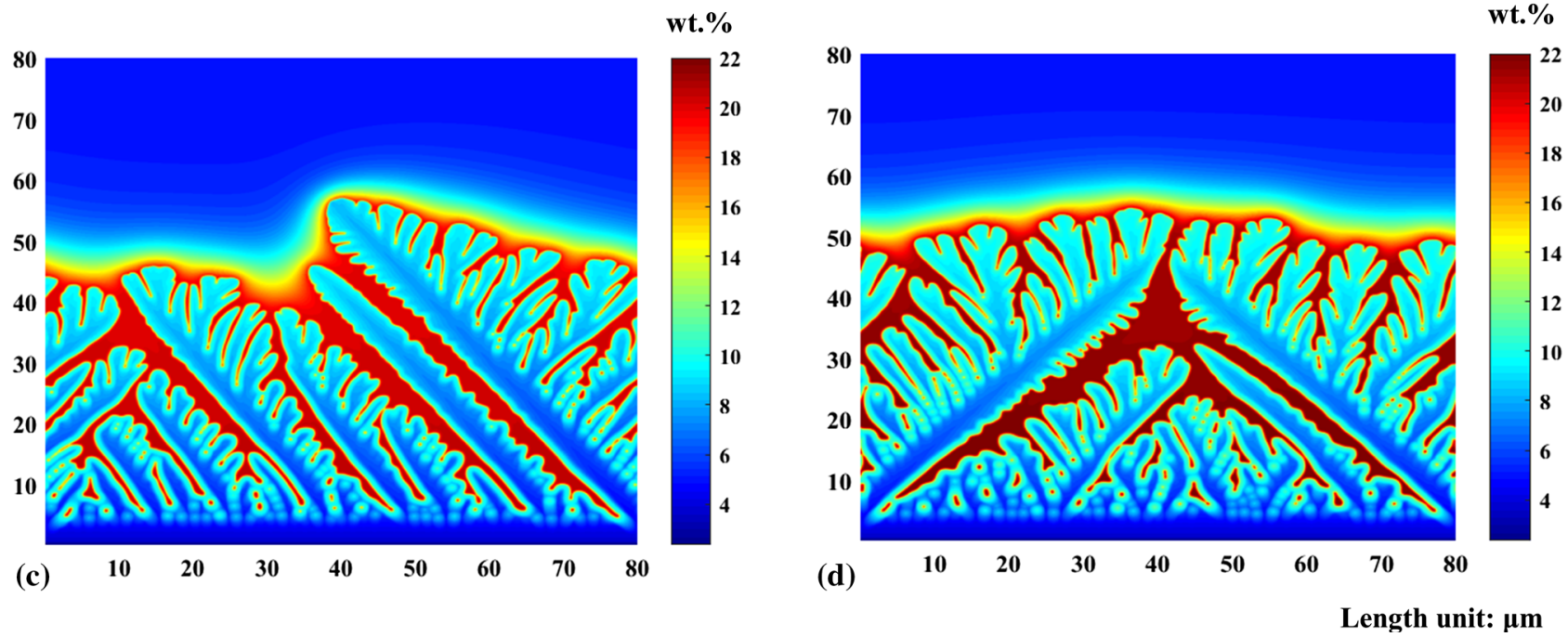

Fig. 5 The solute distribution of $\mathrm{Nb}$ with different misorientation angles: (a) $\theta_{0}=10^{\circ}$; (b) $\theta_{0}=30^{\circ}$; (c) $\theta_{0}=40^{\circ}$; (d) $\theta_{0}=45^{\circ}$. The maximum concentration in each case is: (a) $15 \mathrm{wt} . \%$, (b) $17 \mathrm{wt} . \%$, (c) $20 \mathrm{wt} . \%$ and (d) $22 \mathrm{wt} . \%$, respectively

greater than 23 wt.\% (Ref 17). Thus, in the present simulation, a magnitude of $23 \mathrm{wt} \%$ is set as a criterion of eutectic transformation in IN718 superalloy. That is, liquid with a concentration of $\mathrm{Nb}<23$ wt.\% transforms into the $\gamma$ phase, and liquid with a concentration of $\mathrm{Nb} \geq 23 \mathrm{wt} . \%$ transforms into the Laves phase (Ref 17, 32). Figure 2(e) and (f) shows the final stage of solidification and the distribution of the Laves phase particles (with the local solution field $c>23 \%$ ). Moreover, Fig. 3(a) shows the solute distribution of $\mathrm{Nb}$, and Fig. 3(b) and (c) is the distribution of Laves phase particles under low laser power and high laser power AM (the high laser power generates low cooling rate as $1411 \mathrm{~K} \mathrm{~s}^{-1}$, whereas high cooling rate as $4473 \mathrm{~K} \mathrm{~s}^{-1}$ is from the low laser power). Figure 3(c) shows the solute distribution of $\mathrm{Nb}$, and Fig. 3(e) and (f) is the scanning electron microscopy images from Ref 18. The morphology of the Laves phase particles under different cooling rates is reasonably predicted by the present model showing a good consistency with the previous work and the experimental observations.

\subsection{Micro-segregation Under Different Misorientation Angles and Hot Crack Resistance}

In this section, we simulate the dendrite growth and formation of the Laves phase by choosing the domains with different misorientation angles as $\theta_{0}=10^{\circ}, \theta_{0}=30^{\circ}, \theta_{0}=40^{\circ}$ and $\theta_{0}=45^{\circ}$ due to the fourfold symmetry (without considering the nucleation probability). Figure 4 compares the solidification microstructures at the same height in $z$-direction. The red arrow represents the temperature gradient, and the blue dashed arrow indicates the primary dendrite growth direction. The growth angle between temperature gradient direction and the actual growth direction of primary dendrite is related to $\theta_{0}$ (Ref 33). It can be seen that the primary dendrites growth direction approximately equals to the preferred crystalline orientation rather than the direction of $G$. Meanwhile, the solidification microstructure changes from tilted dendrites (see Fig. 4a) to the degenerated seaweeds (see Fig. 4d) with respect to the misorientation angles. Though the primary dendrite arm spacing is proportional to the $\theta_{0}(\operatorname{Ref} 24,26)$, the gap between 


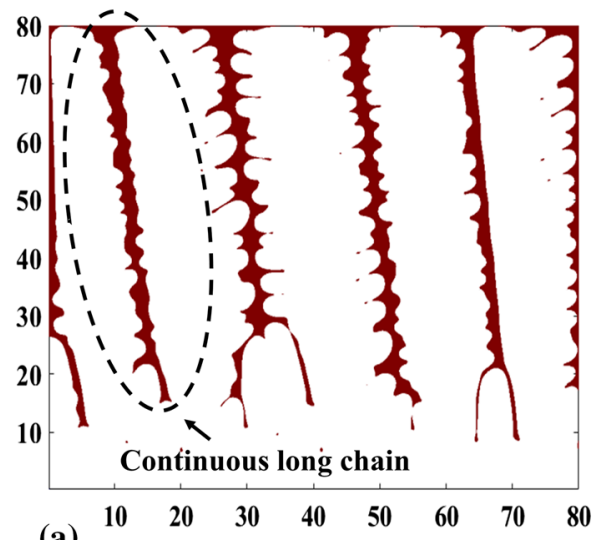

(a)

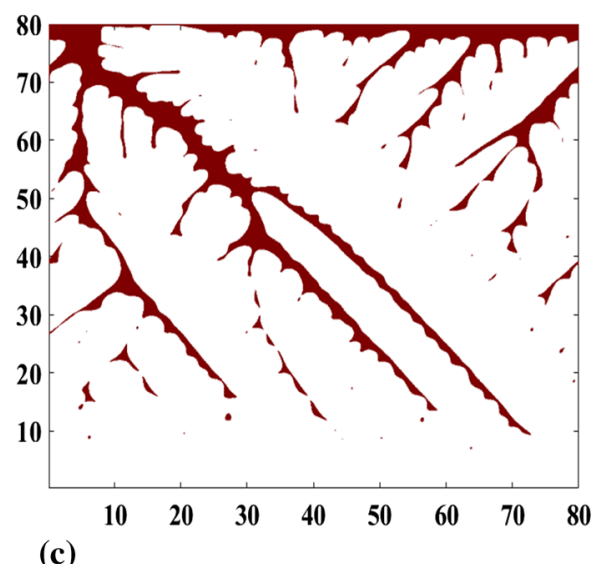

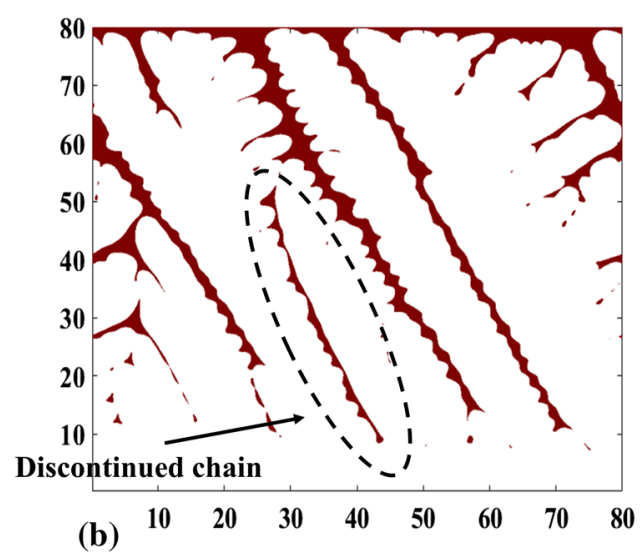

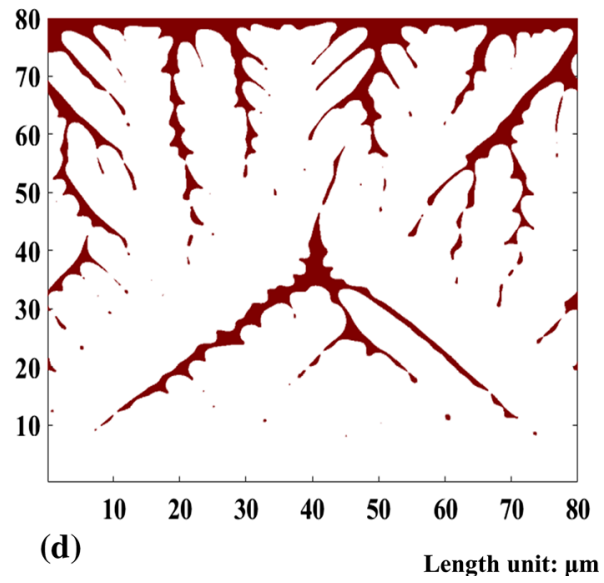

Fig. 6 Formation of the Laves Phase under different misorientation angles: (a) $\theta_{0}=10^{\circ}$; (b) $\theta_{0}=30^{\circ}$; (c) $\theta_{0}=40^{\circ}$; (d) $\theta_{0}=45^{\circ}$

neighboring dendrites is filled by the growing secondary dendrite arms (side branches).

The corresponding $\mathrm{Nb}$ concentration during solidification is given in Fig. 5 for the completeness. The increase in the darkness of red colors in the inter-dendritic region with the increase in misorientation angle indicates that the larger the misorientation angle is, the higher the solute concentration of $\mathrm{Nb}$ in the liquid becomes (with the maximum concentrations as (a) 15 wt.\%, (b) 17 wt.\%, (c) 20 wt.\% and (d) 22 wt.\%). It can be explained in twofold: First, the dendrites grow faster with a small misorientation angle, giving less time for high $\mathrm{Nb}$ concentration to build up. Second, a complex local microstructure formed at high misorientation angles $\left(45^{\circ}\right)$ prevents $\mathrm{Nb}$ being further diluted to the liquid far away from the solidliquid interface, i.e., two neighboring primary dendrites enclose large amount liquid in the middle, as shown in Fig. 5(d).

The growth of side branches can effectively reduce the formation of the Laves phase particles with long chain morphology, as shown in Fig. 6. The distribution of Laves phase particles is dominated by the continuous long chain at $\theta_{0}=10^{\circ}$, as the total number of continuous long chains is six (see Fig. 6a). As the angle reaches $30^{\circ}$, a long chain is separated by the growth of secondary dendrite arms into a shorter one (see Fig. 6b). It is similar to the findings of previous work that the side branches are beneficial to the formation of discrete Laves phase particles (Ref 23), because in the growth of tilted dendrite, the side branches of two neighboring parallel dendrites are less developed to separate nearby liquid into several regions. Therefore, when the misorientation angles reach $40^{\circ}$ and $45^{\circ}$ (Fig. $6 \mathrm{c}$ and d), more side branches join neighboring dendrites and, hence, squeeze more liquid into the relatively isolated, discrete regions (or shorter chains). Consequently, the probability of the formation of the Laves phase particles with long continuous chain morphology is reduced. This finding shows that the solidification sites with large misorientation angles have less possibility of forming Laves phase particles with long continuous chain morphology during solidification. The hot cracking is usually found in the microstructure that contains Laves phase particles with long continuous chain morphology, but the cracking is not often observed in the microstructure with the discrete distribution of Laves phase. Avoiding the long continuous chain morphology can improve the hot cracking resistance of IN718 alloy (Ref 23). Hence, large misorientation angle can improve the hot cracking resistance of IN718 alloy by reducing the formation of Laves phase with long continuous chain morphology.

\section{Conclusion}

In this work, we studied the influence of solidification site on the morphology of solidification structures and formation of Laves phase of IN718 alloy during laser AM. A multi-scale model combining FEM and PFM was applied. The FEM was used to obtain the geometry and the temperature gradient $G$ due 
to laser scanning. Then, the results were employed as inputs to PFM. Finally, the morphology of solidification structures and formation of Laves phase at different misorientation angles were compared. We found that the solidification site with large misorientation angle could build up higher solute concentration in the liquid during solidification but with less possibility of forming continuous long chain morphology of Laves phase particles. Further, it indicated that, after solidification, those possible sites with low hot crack resistance may have large angle between the temperature gradient $G$ and the preferred crystalline direction during solidification. This investigation provided an understanding of the microstructure evolution inside molten pool of IN718 alloy during solidification.

\section{Acknowledgments}

This work is financially supported by the program of ORAU Ralph E. Powe Junior Faculty Enhancement Award and NSF CMMI 1662854. The computer simulations were carried out on the clusters of High Performance Computing Collaboratory $\left(\mathrm{HPC}^{2}\right)$ at Mississippi State University. MFH recognizes the Center for Advanced Vehicular Systems (CAVS) at Mississippi State University for support.

\section{Appendix: Nucleation}

The number of grains, $\partial N_{1}$ and $\partial N_{\mathrm{i}}$, that nucleate in the volume of the liquid and at the solid/liquid interface during each time step is calculated by using nucleation site distributions, $N_{\mathrm{l}}(\Delta T)$ and $N_{\mathrm{i}}(\Delta T)$, respectively. These distributions can be calculated assuming some experimental approaches similar to those already used in deterministic models of solidification (Ref 23, 32). Note that the solidification analysis is based on the assumption of no grain movement in the liquid, and the nucleation rate is (Ref 32)

$\frac{\partial N}{\partial t}=-2 \mu_{\mathrm{N}} \Delta T \frac{\partial T}{\partial t}\left(1-f_{\mathrm{s}}\right)$

where the $N$ is the number of the nuclei (note that we apply $N_{l}$ and $N_{i}$ as the nuclei number in the liquid phase and at the interface, respectively) and the $f_{\mathrm{s}}$ is the fraction of solid. $\mu_{\mathrm{N}}$ is a nucleation parameter (in the liquid phase: $\mu_{\mathrm{N}}^{1}=10^{3} \mathrm{~K}^{-2}$ $\mathrm{m}^{-2}$ or at the interface: $\mu_{\mathrm{N}}^{\mathrm{i}}=5 \times 10^{5} \mathrm{~K}^{-2} \mathrm{~m}^{-2}$ ) (Ref 23). $\partial T / \partial t$ is the undercooling rate and $\Delta T$ denotes the local undercooling.

The nucleation probabilities in liquid and at the interface are given as follows, respectively,

$d p_{1}=\frac{\partial N_{l}}{N^{10}-N^{\mathrm{i} 0}}$ and $d p_{\mathrm{i}}=\frac{\partial N_{\mathrm{i}}}{N^{\mathrm{i} 0}}$

where $N^{10}$ and $N^{i 0}$ are the number of the nodes in the bulk liquid and at the interface, respectively. In order to predict the nucleation, a random number that ranges from 0 and 1 is generated by computer and compared to the magnitude of $d p_{1}$ or $d p_{i}$, corresponding to probabilities in the liquid and at the interface, respectively. Once the random number is greater than $d p_{1}$ or $d p_{\mathrm{i}}$, nucleation occurs in the liquid or at the interface.
Note that $\mathrm{Nb}$ is segregated into the liquid that controls the formation of the Laves phases (Ref 13). Other elements, i.e., Fe and $\mathrm{Ti}$, can also contribute to the formation of Laves phase. It has been, however, revealed that the formation of Laves phase is mainly controlled by the segregation of $\mathrm{Nb}$ ( $\operatorname{Ref} 13,15-17)$. Thus, in this paper, for the IN718 superalloy, we will focus on the segregation of $\mathrm{Nb}$.

\section{References}

1. Y.N. Zhang, X. Cao, P. Wanjara, and M. Medraj, Oxide Films in Laser Additive Manufactured Inconel 718, Acta Mater., 2013, 61(17), p 6562-6576

2. T.E. Abioye, J. Folkes, and A.T. Clare, A Parametric Study of Inconel 625 Wire Laser Deposition, J. Mater. Process. Technol., 2013, 213(12), p 2145-2151

3. R.J. Moat, A.J. Pinkerton, L. Li, P.J. Withers, and M. Preuss, Crystallographic Texture and Microstructure of Pulsed Diode LaserDeposited Waspaloy, Acta Mater, 2009, 57(4), p 1220-1229

4. T. Baldridge, G. Poling, E. Foroozmehr, R. Kovacevic, T. Metz, V. Kadekar, and M.C. Gupta, Laser Cladding of Inconel 690 on Inconel 600 Superalloy for Corrosion Protection in Nuclear Applications, Opt. Lasers Eng., 2013, 51(2), p 180-184

5. A. Chamanfar, L. Sarrat, M. Jahazi, M. Asadi, A. Weck, and A.K. Koul, Microstructural Characteristics of Forged and Heat Treated Inconel-718 Disks, Mater. Des., 2013, 1980-2015(52), p 791-800

6. K.N. Amato, S.M. Gaytan, L.E. Murr, E. Martinez, P.W. Shindo, J. Hernandez, S. Collins, and F. Medina, Microstructures and Mechanical Behavior of Inconel 718 Fabricated by Selective Laser Melting, Acta Mater., 2012, 60(5), p 2229-2239

7. Y. Lee, M. Nordin, S.S. Babu, and D.F. Farson, Effect of Fluid Convection on Dendrite Arm Spacing in Laser Deposition, Metall. Mater. Trans. B, 2014, 45(4), p 1520-1529

8. Y.-J. Liang, X. Cheng, and H.-M. Wang, A New Microsegregation Model for Rapid Solidification Multicomponent Alloys and Its Application to Single-Crystal Nickel-Base Superalloys of Laser Rapid Directional Solidification, Acta Mater, 2016, 118, p 17-27

9. T. Keller, G. Lindwall, S. Ghosh, L. Ma, B.M. Lane, F. Zhang, U.R. Kattner, E.A. Lass, J.C. Heigel, and Y. Idell, Application of Finite Element, Phase-Field, and CALPHAD-Based Methods to Additive Manufacturing of Ni-Based Superalloys, Acta Mater, 2017, 139, p 244-253

10. P.W. Liu, Y.Z. Ji, Z. Wang, C.L. Qiu, A.A. Antonysamy, L.Q. Chen, X.Y. Cui, and L. Chen, Investigation on Evolution Mechanisms of SiteSpecific Grain Structures During Metal Additive Manufacturing, J. Mater. Process. Technol., 2018, 257, p 191-202

11. A. Badillo and C. Beckermann, Phase-Field Simulation of the Columnar-to-Equiaxed Transition in Alloy Solidification, Acta Mater., 2006, 54(8), p 2015-2026

12. H. Xing, X.L. Dong, C.L. Chen, J.Y. Wang, L.F. Du, and K.X. Jin, Phase-Field Simulation of Tilted Growth of Dendritic Arrays During Directional Solidification, Int. J. Heat Mass Transf., 2015, 90, p 911921

13. G.A. Knorovsky, M.J. Cieslak, T.J. Headley, A.D. Romig, and W.F. Hammetter, INCONEL 718: A Solidification Diagram, Metall. Trans. A, 1989, 20(10), p 2149-2158

14. R.W. Caless, J.J. Schirra, and R.W. Hatala, Superalloys 718, 625 and Various Derivatives, TMS, Warrendale, 1991

15. L. Nastac, Numerical modeling of solidification morphologies and segregation patterns in cast dendritic alloys, Acta Mater., 1999, 47(17), p 4253-4262

16. L. Nastac and D.M. Stefanescu, Macrotransport-solidification kinetics modeling of equiaxed dendritic growth: part I. Model development and discussion, Metall. Mater. Trans. A, 1996, 27(12), p 4061-4074

17. J.N. DuPont, C.V. Robino, and A.R. Marder, Modeling Solute Redistribution and Microstructural Development in Fusion Welds of Nb-Bearing Superalloys, Acta Mater, 1998, 46(13), p 4781-4790

18. L. Chen, F. Fan, L. Hong, J. Chen, Y. Ji, S. Zhang, T. Zhu, and L. Chen, A Phase-Field Model Coupled with Large Elasto-Plastic 
Deformation: Application to Lithiated Silicon Electrodes, J. Electrochem. Soc., 2014, 161(11), p F3164-F3172

19. L. Chen, H.W. Zhang, L.Y. Liang, Z. Liu, Y. Qi, P. Lu, J. Chen, and L.-Q. Chen, Modulation of Dendritic Patterns During Electrodeposition: A Nonlinear Phase-Field Model, J. Power Sources, 2015, 300, p 376-385

20. Y. Ji, L. Chen, and L.-Q. Chen, Understanding microstructure evolution during additive manufacturing of metallic alloys using phase-field modeling, Thermo-Mechanical Modeling of Additive Manufacturing, M. Gouge and P. Michaleris, Ed., Elsevier, Amsterdam, 2018, p 93-116

21. Y.Z. Ji, Z. Wang, B. Wang, Y. Chen, T. Zhang, L.Q. Chen, X. Song, and L. Chen, Effect of Meso-Scale Geometry on Piezoelectric Performances of Additively Manufactured Flexible Polymer$\mathrm{Pb}\left(\mathrm{Zr}_{\mathrm{x}} \mathrm{Ti}_{1-x}\right) \mathrm{O}_{3}$ Composites, Adv. Eng. Mater, 2017, 19(6), p 1600803

22. X. Wang, B. Wang, M. Meyerson, C.B. Mullins, Y. Fu, L. Zhu, and L. Chen, A Phase-Field Model Integrating Reaction-Diffusion Kinetics and Elasto-Plastic Deformation with Application to Lithiated SeleniumDoped Germanium Electrodes, Int. J. Mech. Sci., 2018, 144, p 158-171

23. P. Nie, O.A. Ojo, and Z. Li, Numerical Modeling of Microstructure Evolution During Laser Additive Manufacturing of a Nickel-Based Superalloy, Acta Mater., 2014, 77, p 85-95

24. S. Ghosh, L. Ma, N. Ofori-Opoku, and J.E. Guyer, On the Primary Spacing and Microsegregation of Cellular Dendrites in Laser Deposited Ni-Nb Alloys, Model. Simul. Mater. Sci. Eng., 2017, 25(6), p 065002

25. D. Tourret and A. Karma, Growth Competition of Columnar Dendritic Grains: A Phase-Field Study, Acta Mater., 2015, 82, p 64-83
26. F. Yu, Y. Wei, Y. Ji, and L.-Q. Chen, Phase Field Modeling of Solidification Microstructure Evolution During Welding, J. Mater. Process. Technol., 2017, 255, p 285-293

27. N. Raghavan, R. Dehoff, S. Pannala, S. Simunovic, M. Kirka, J. Turner, N. Carlson, and S.S. Babu, Numerical Modeling of HeatTransfer and the Influence of Process Parameters on Tailoring the Grain Morphology of IN718 in Electron Beam Additive Manufacturing, Acta Mater., 2016, 112, p 303-314

28. B. Echebarria, R. Folch, A. Karma, and M. Plapp, Quantitative PhaseField Model of Alloy Solidification, Phys. Rev. E Stat. Nonlinear Soft Matter Phys., 2004, 70(6 Pt 1), p 061604

29. W. Zheng, Z. Dong, Y. Wei, K. Song, J. Guo, and Y. Wang, Phase Field Investigation of Dendrite Growth in the Welding Pool of Aluminum Alloy 2A14 Under Transient Conditions, Comput. Mater. Sci., 2014, 82, p 525-530

30. N.J. Harrison, I. Todd, and K. Mumtaz, Reduction of Micro-cracking in Nickel Superalloys Processed by Selective Laser Melting: A Fundamental Alloy Design Approach, Acta Mater., 2015, 94, p 59-68

31. W. Kurz and R. Trivedi, Rapid Solidification Processing and Microstructure Formation, Mater. Sci. Eng. A, 1994, 179, p 46-51

32. L. Nastac and D.M. Stefanescu, Stochastic Modelling of Microstructure Formation in Solidification Processes, Model. Simul. Mater. Sci. Eng., 1997, 5(4), p 391

33. J. Deschamps, M. Georgelin, and A. Pocheau, Growth Directions of Microstructures in Directional Solidification Of Crystalline Materials, Phys. Rev. E, 2008, 78(1), p 011605 